\title{
Lived Experiences of Parents with Children Diagnosed with Cancer in Trinidad: Challenges and Coping Strategies
}

\author{
Philip Onuoha ${ }^{1}$, Gloria Ramdeen-Mootoo ${ }^{1}$, Denise Alexander ${ }^{1}$, Dana Ali-Jadoobir ${ }^{1}$, Greer Bain Bedeshi ${ }^{1}$, \\ Natasha Lyder-George ${ }^{1}$, Chivonne Mitchell ${ }^{1} \&$ Tricia Vitalis $^{1}$ \\ ${ }^{1}$ The UWI School of Nursing, The University of the West Indies, St. Augustine, Trinidad and Tobago \\ Correspondence: Dr Philip Onuoha, UWI School of Nursing, Faculty of Medical; Sciences, The University of \\ the West Indies, St. Augustine, Trinidad and Tobago. Tel: 1-868-225-1026. E-mail: Philip.onuoha@ sta.uwi.edu
}

$\begin{array}{lc}\text { Received: April 6, } 2018 & \text { Accepted: April 20, } 2018 \quad \text { Online Published: May 4, } 2018 \\ \text { doi:10.5539/cco.V7N2p1 } & \text { URL: https://doi.org/10.5539/cco.V7N2p1 }\end{array}$

\begin{abstract}
Aim: The aim of this study is to explore the lived experiences of parents pertaining to how cancer in their family affected their lives. In particular the study detailed the participants' challenges and the strategies they adopted in dealing with the challenges. Methodology: An exploratory phenomenology method was used to guide the study. The participants were selected from the Paediatric Oncology Clinic at The Wendy Fitzwilliam's Paediatric Hospital. Triangulation of different strategies namely, a focus group interview and four key informant interviews were utilized to collect data from ten parents. The data was audiotaped, transcribed and organized into codes and themes. Results: In the main, findings revealed three main themes: reliance on spirituality to cope, psychosocial challenges, and social support system. This study revealed that the lived experiences of parents who care for their children diagnosed with Cancer, are like a never-ending struggle. Discussion: Regardless of the substantial progress in the treatment of Cancer, childhood Cancer is still emotionally, physically, and psychologically challenging for parents and nurses. This was discussed vis a vis literature. Recommendation: The themes highlighted offer opportunities for additional qualitative and quantitative research in the field of oncology and its impact on Trinidadian parents and the Trinidad family system and dynamics. However, further research is needed from the nursing perspective to focus on paediatric oncology.
\end{abstract}

Keywords: cancer, coping mechanism, challenges, lived experiences, Trinidad

\section{Introduction}

Once a child is diagnosed with Cancer, it is inevitable for parents to become emotionally affected. Childhood Cancer usually presents itself unexpectedly, giving parents little opportunity to prepare for the demands of caring for their newly diagnosed child. Most of the time, doctors do not know why children are diagnosed with Cancer since the cause of Cancer in children are not the same as those in adults such as smoking or exposure to environmental toxins (National Cancer Institute, 2016). Studies investigating the psychosocial outcomes of Cancer seems to support the obvious; that Cancer has a major impact on the lives of stricken individuals and families (Cho, S, Yang M, Yim S, Park J, Lee J, Eom Y, Jang, I. Kim H et al (2009). Even with good prognosis of childhood Cancer; diagnosis, treatment and hospitalization affects the life situation of the entire family. In this regard, parents must acquire knowledge about Cancer so that they can manage and care for their children with Cancer. This is further reinforced by the parents needs to cope with anxieties, fears, and frustrations brought about by interactions with the affected child, while integrating the child's needs into established family routines plus managing the strain in social and/or family life (Cho, S, Yang M, Yim S, Park J, Lee J, Eom Y, Jang, I. Kim $\mathrm{H}$ et al (2009).

Globally childhood Cancers make up less than $1 \%$ of all Cancers diagnosed each year (Siegel R, Miller K, and Jemmal A (2016). About 10,380 children in the United States under the age of 15 will be diagnosed with Cancer in 2016. Cancer is the second leading cause of death in children aged 1 to 14. About 1,250 children younger than 15 years old are expected to die from Cancer in 2016 (Siegel R, Miller K, and Jemmal A (2016). Because of major treatment advances in recent decades, more than $80 \%$ of children with Cancer now survive 5 years or more. Overall, this is a huge increase since the mid-1970s, when the 5-year survival rate was about $58 \%$.

Childhood Cancer cases (65\%) occurs in Latin America and the Caribbean, where it is estimated that 17,500 children newly diagnosed and over 8000 children were dying from the disease each year (Cayon, 2017). One of 
the greatest barriers to better childhood Cancer survival in Latin America and the Caribbean is abandonment of treatment, due to high cost as well as limited availability of equipment, (Cayon, 2017).

In 2017 the Pan American Health Organization formed a group PAHO's Childhood Cancer Working Group with the main aim to improving access to care for children with Cancer and reducing inequalities associated with the outcomes for children with Cancer in Latin America and the Caribbean (Cayon, 2017). .

Cases in Trinidad and Tobago are rising. In a study done in 2010 by the Child Health Unit, Faculty of Medical Sciences, The University of the West Indies St Augustine, Trinidad and Tobago on the Incidence of Childhood Cancer in Trinidad and Tobago, indicated that the highest incidence was in children < 5years: 14 per 100,000 for males and 11.4 per 100,000 for females. Leukemias and central nervous system tumours formed the majority of the Cancers (58.56\%), however nephroblastoma was more common than neuroblastoma especially in females < 5 years (Bodkyn and Lalchandi, 2010). According to a report on the Situational Analysis of Children and Women in Trinidad and Tobago, the total number of Cancers diagnosed in children 0- 19 years old were 275 cases in male, 216 cases in females for the period 1995-2006. This represented an increase in up to 2.2 percent of all cases for that period. Theodore, Gittens-Bayne, Edwars-Wescotts, Mc Clean, \& Laptiste, (2011) indicated that although these numbers are relatively small, the disease is much more prevalent in young children than other chronic diseases such as diabetes or hypertension.

We have observed that parents living with children diagnosed with Cancer in Trinidad very often show signs of frustration, anger and pain. There appears to be insufficient information pertaining to how parents cope with their children's Cancer in Trinidad. With the advances in science and technology and the introduction of advance treatment, parents are given the hope that Cancer diagnoses is not a death sentence and that their children can live still long healthy meaningful lives. Also, children with cancers in Trinidad and Tobago attend schools to gain education like other children with a chronic disease, notwithstanding that they may lose many school days when they are seeking medical treatment. Although, the government of Trinidad and Tobago ensures that all children are not denied the compulsory public education as contained in the Education Act of Trinidad and Tobago (ref. Act of Trinidad ministry of Education Act 39:01 of the laws of Trinidad and Tobago, this by itself may have exposed the children to some social concerns which will add to the concern of the parents. A non-Governmental Organisation named "The Just Because Foundation" (JBF) was established 2007 by Noel and Chevaughn Joseph, whose son after a tenacious two year battle, lost their $51 / 2$ year old son Jabez "JB" Joseph, to Alveolar Rhabdomyosarcoma with the aim of assisting the families living with paediatric cancers in their coping issues. There has not been any study that attempt to document the challenges faced by the parents with children with cancers, as well how these parents are coping with those challenges.

This study is an attempt to document the experiences of the parents with children diagnosed with cancer regarding their challenges and coping strategies used.

\section{Purpose}

This study sought to explore the lived experiences of parents with children diagnosed with Cancer in Trinidad. It also sought to document the coping strategies and challenges they faced, the type of support they had if any, and how they managed through this difficult experience.

Objectives:

1. To explore the experiences of parents manage with their children diagnosed with Cancer in Trinidad.

2. To identify the challenges faced by the parents whose children are diagnosed with Cancer in Trinidad.

3. To describe coping mechanisms used by the parents whose children are diagnosed with Cancer, in Trinidad.

\section{Research Questions}

1. How do the parents of children diagnosed with cancer cope with the experience of their children diagnosed with cancer?

2. What are the challenges faced by parents whose children have been diagnosed with Cancer?

3. What support do the parents of children diagnosed with cancer receive from the society?

\subsection{Conceptual Framework}

We conceptualize the experiences of parents of paediatric Cancer in a holistic manner. We took into consideration their bodies, mind, emotions, relationships, and spirituality. As used in our diagram below, our dependent variables were the challenges of parents with children diagnosed with Cancer and coping mechanisms used by parents or guardian caring for children with Cancer. Using a holistic approach, we used our independent 
variables to get a true understanding of what their lives are like. Our Independent variables lead us into three themes which are; Reliance on Spirituality to Cope, Psychosocial Challenges and the presence of Social Support Systems.

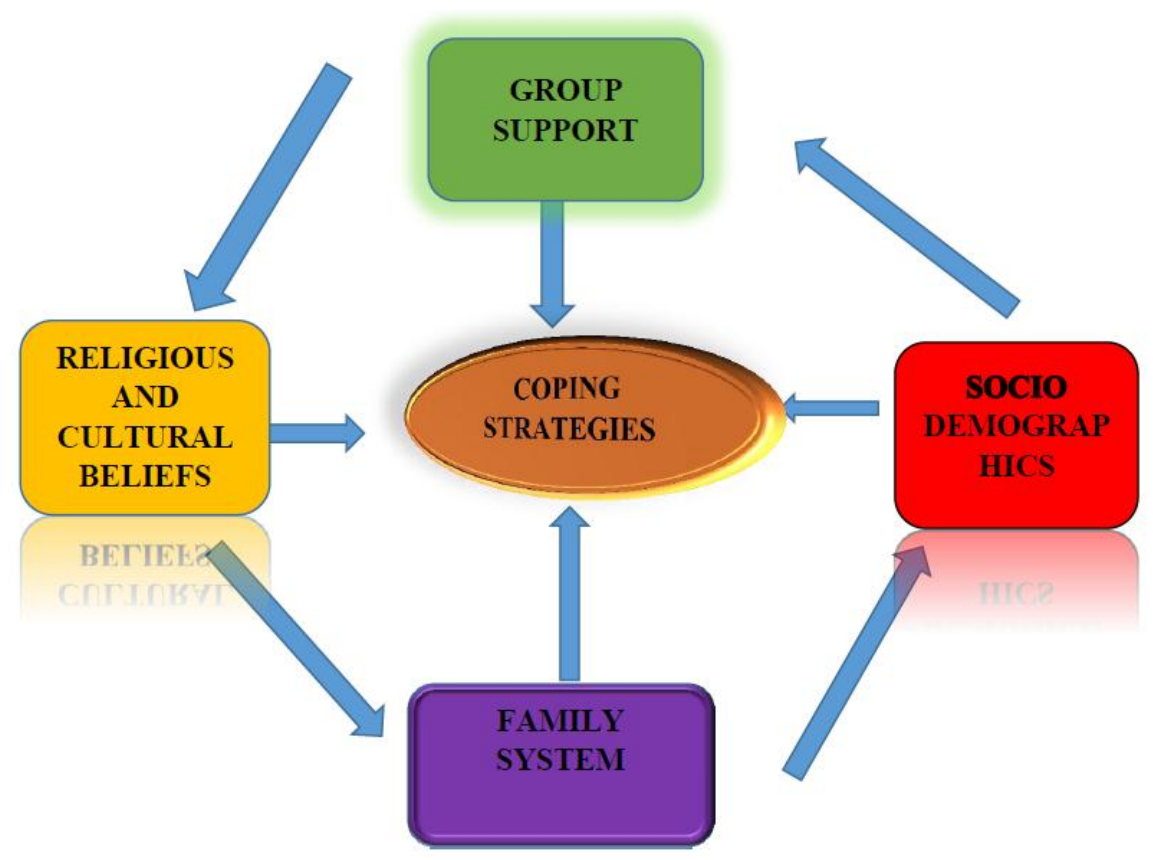

Figure 1. CONCEPTUAL FRAMEWORK

\subsection{Theoretical Framework}

In this study, we used the Biopsychosocial Spiritual Model as the theoretical framework. It involved the use of various components that make up the lived experiences of parents whose children are diagnosed with Cancer. The biopsychosocial framework was first introduced George L. Engel in 1977. It informs that interactions between biological, psychological, and social factors determine the cause, manifestation, and outcome of wellness and disease. Engel's theory was extended by subsequent authors to include the spiritual context in addition to the biological, psychological, and social dimensions. In this study, we looked at how the themes identified by our research participants represented the challenges they faced while living with the condition in their family as well as their coping strategies as the Biopsychosocial Spiritual Model consists of the physical systems comprising an individual's biology (Zemerleri and Ryan (2016). For example subatomic particles such as atoms, molecules, cells, tissues, organs, organ systems, and the nervous system); an individual's mental state (both cognitive and emotional); an individual's relationships with others (e.g. family, friends, community, culture, and society); and an individual's spirituality as defined by their sense of connection with a transcendent and inspiring force capable of bringing meaning to one's life and shaping the way one behaves and operates in the world (Meireles et al., 2015; Austin, Onuoha and Dyer-Regis (2016).

\section{Methodology}

\subsection{Research Design}

This study utilizes a Qualitative Phenomenological approach describing the lived experiences of parents with children diagnosed with Cancer which allows researchers to gather data that are subjective, meaningful and of substance, while focusing on the lived experiences of people (Onuoha, Dyer Regis \& Onuoha, 2017; Polit \& Beck, 2008).

\subsection{Sampling}

The participants of the study were purposely selected from the Oncology Clinic at The Wendy Fitzwilliam's Paediatric Hospital because the JBF housed the children diagnosed with Cancer. Prospective participants were identified by the Head Nurse of the JBF Oncology Clinic and conveniently sampled based on parents' willingness to participate in the study. The purpose of the interview was explained to the participants; and their ability to articulate their feelings and experiences living with their children with Cancer the interview gauged. 
Participants consisted of parents of children from age three to fifteen living with Cancer. They were four (4) key informants, four (4) females and one (1) focus group comprising, four (4) females and two (2) males. These individuals were all parents of children living with Cancer. This sampling was more or less criterion-referenced as the participants' must have children diagnosed with cancers (Polit \& Beck, 2018).

\subsection{Data Collection Strategy}

A form of triangulation was utilized for data collection as a face-to-face interviews were carried out with key informants, as well as a focus group interviews with research participants (Onuoha, et al, 2017). The four key informants' interviews were done first in the privacy and comfort of their homes at different locations in Trinidad name, Arima, Sangre Grande, San Fernando and St. Joseph. The interviews lasted between forty to forty-five minutes. This was followed by the Focus Group Interview conducted at The Wendy Fitzwilliam Paediatric Hospital Oncology Clinic location. The interview lasted approximately I hour. The period of data collection was 3 weeks and the ages of the children whose parents participated ranged from $6-15$ years.

Demographic data was given via the Head Nurse of the clinic. Parents who met the criteria, having a child diagnosed with Cancer age three to fifteen years and lives in in the east west, north or south Trinidad was approached, informed about the study and if willing to participate were briefed on the all criteria. Participants gave consent by signing the relevant prepared consent form to participate in the study as outlined. Before signing forms, verbal consent was given and any issues that may arise was discussed before they confirmed giving consent. Respondents were given details of the research interview and the need for audiotaping of their responses. Anonymity and confidentiality were assured throughout. Respondents introduced themselves prior the interview and consented by signing their legal names on the forms provided. However during the interview, respondents were identified by numbers only when audiotaped. Example; responder one, responder two, responder ten. We utilized open-ended questions which provided the opportunity for parents to discuss particular topics in detail. All responses were reviewed and analysed for recurrent themes. These items were previously pretested and deemed to have face and content validity.

\subsection{Informant Profiles}

The profiles below is a brief descriptive summary of the four key informants who participated in our study. They are identified as informant 1-4.

Informant 1- a 47-year old employed female, whose daughter was only twelve years when she was diagnosed with Cancer. The interview was held in the privacy of her own home in Sangre Grande. She lives with her son and her husband, who is her daughter's step-father. The environment was clean and comfortable. The interview took place between 5-6pm after she had finished all her chores. The participant was very willing to participate in the research study. She was calm when speaking about the experiences, at times she even smiled. At times she would cry and even had blanked stares for some questions. She was surrounded by support from her family members, she even mentioned that she was happy to be part of the research.

Informant 2- a 51-year old female employed and lives in the Arima area. She is a single parent whose son was diagnosed at the age of eleven. The interview took place at her home 9am. The child's father was always there to support both the mother and his child during the sickness. There was a lot of support from her family members and relatives. Support also came from her two churches and their members. There was support from her co-workers as well. There was no reluctance from her to share her information, and she answered all questions comfortably, and was not prompted at any point. She seemed comfortable speaking of her experiences.

Informant 3- a 32-year old employed female with a three year old daughter diagnosed with Cancer. She is a single mother that lives alone with not much support from her child's father. The interview was conducted at in her home in Maracas, St. Joseph in the evening time around 6:00 pm. Her main support was from God and a friend. At the time of the interview the child was somewhat distraught and did not seem to be doing well. She confided that she was having some financial constraints. She appeared to be in total denial and verbalized that she was angry because of her child's tender age; however she was cooperative during the entire interview.

Informant 4- a 35-year old employed female, who was married at twenty one years of age and lives in Point Fortin. Her first child a son, was diagnosed with Cancer at the age of eight months. The interview was conducted in a private room at her workplace in San Fernando at 10am. She was very happy to share the information of her experience with the interviewers.. Her answers where forthcoming and she did not have to be prompted. She smiled when she spoke of her child and her faith in God. She had a lot of support from her husband and family, but none from her employers.

\section{Results}


After the interviews were completed, the data collected on the audio recorder were replayed a few times to get a clear understanding of the responses before it was transcribed. Within each transcripts, codes were identified and then placed into themes. Three transcripts were made from the focus group under the identified themes were (a) reliance on spirituality to cope; (b) psychosocial Challenges; and (c) social support systems available.

\section{Research question one: what challenges do you face while living in this condition with your child diagnosed with cancer?}

The main theme in response to this question was psychosocial challenges.

Parents learning that their child is diagnosed with Cancer, have effects not only on their emotions, but changes occur to their social life with their families and friends. These changes were expressed by the participants as they related how the diagnosis of their child's illness affected their social life. Respondent five (5) stated that: "I used to be able to go out and "lime" (colloquial meaning spending time socializing) with friends, now I'm always at home or in the hospital." Another key informant verbalized that: "One day your life was normal and upon the diagnosis of paediatric Cancer it went topsy turvy." A key informant recalls sometimes when she left to go somewhere, she would get a phone call stating her child has fever and have to go back into the hospital, sometimes for two weeks. She says "this is the reason I do not go anywhere, just stay home and not even go to church." Another example of psychosocial challenge expressed by respondent one: "It becomes top secret that even if someone wants to come in and assist, you would not allow them. Some people would ask to help but I thought they wanted to mind my business. Probably they would have been able to lend support if I had opened up some more."

It is worth noting that mothers and fathers face distinct demands and tend to deal differently with challenges. Most mothers usually assume the role of primary caregiver and become emotionally involved while the fathers act as providers and tend to distance themselves emotionally from the situation. The challenges for the mothers are mainly related to decision-making, administration of medication, promotion of comfort and support, planning of family activities, handling the children's behavioural problems, paying attention to intercurrences, and supervising routine responsibilities. This was reflected by the mothers: responder six says: "I remember her father use to be around even her grandfather but she would want me to bathe her. Mammy come and bathe meh". Another key informant child was very attached to mother and preferred her only to do things for her. It was noted that daughters felt much safer and secure around their mothers.

Parents report higher levels of anxiety, whether at the time the diagnosis is disclosed or in other stages of the disease. These manifestations of feeling were verbalized when asked how you cope with the daily management of both family and nursing a sick child. Respondent six shared her experience of crying out for help with her daughter's poor eating pattern; she stated, "as a mother there is only healthy stuff in my house lots of fruits and vegetables. I am a chef by profession so I knew about keeping her diet on a level. When my daughter was not eating something wrong". Another mother shared same concern regarding not eating hospital meals she says " my daughter will not eat hospital food,so my mother is one used to cook and I go collect food for her ".

That emotionally stressed out this parent because at times her daughter refused the hospital's food and waited on her mother's home cooked meals. Another stated: "my child not eating properly sometimes you eat a sandwich, sometimes you just don't eat". The feeling of anxiety was unanimous amongst mothers verbalizing, "If it was not the Cancer giving you stress, it was the other avalanche of things associated with it". Some fathers faced conflict between working and staying in the hospital, in addition to the demand to provide emotional support to his wife and other children. Respondent three conveyed his experience expressing physical support to his son; "I had to show him I am there to support and I ended up taking one of the tablets. Sit with him to take meal. Like today I ate breakfast with him. " Supporting his child by showing him that the medication will not make him sick or, cause harm but instead help him get better showed the length he was willing to go to show support.

Children often adapt better to a hospital if their parents stay with them for as long as possible. Reassuring the child that you will be staying by his side, and let him know the hospital is a safe place to be. Due to this fact the demand of so much time in hospital required for treatment, parent's responses were; key informant two: "You have to be there with child 24/7 to make sure he get optimum care". Respondent five: "I was restricted I could not go anywhere he needs me so you have to be in the hospital for most of the duration. Key informant two: "I stay there for the entire month once I left him by the time you back home you have to watch him you have to check for fever". Key informant three: "You were strictly informed that you cannot go anywhere". The challenge was one according to one Key informant's experience in the hospital, "...basically not wanting to leave the room, would stay whole day, just to have a bath, eat something if somebody brought something and back in" thus parents' demand of time is one of the challenges they faced. 
Research question 2: How do you cope with this experience of your children being diagnosed with cancer? In discussing this question among themselves, the following theme was identified: "reliance on spirituality to cope "

Many parents first felt alone and disappointed with God, while some were trying to understand how God can allow an innocent child to have a terminal illness. As one parent explained; “...initially I felt that God had failed me, I had to keep reminding myself there is a God, because I couldn't get, how my three year old could be that ill and God will allow that".

Some of the parents interviewed shared that their reliance on spirituality to cope was helpful. The primary theme "Strong faith in God and faith was increased" describes the feelings of faith and spirituality by parents as they repeatedly verbalized this sentiment. Parents from both the focus group and key informant shared their experiences on spirituality as it relates to their coping and challenges with their children's Cancer. As parents tried to understand how the diagnosis of Cancer has impacted negatively on their lives and of their children, they turn to religious belief as their source of comfort and strength to deal with their inner grief.

One parent described her experience of spiritual support in the following way; "I realised that God was still there, it brought me closer, I realised that my faith in God was strengthened, I was strengthened and increased others faith". Another example of parents' reliance on spirituality to cope comes from a mother whose only child died at age fourteen from Acute Lymphoid Leukaemia. She said, "God give me the opportunity to have him for 14yrs I'm always grateful for that. Some people never had the opportunity to have a child, they never know what it is to be a mother I know what it is I know labour pain and I am thankful unto God daily from him. God feel free to take him back. I give God praise and honour for that. I have come to trust in him so that I have grown throughout the process I have left from one level to a higher level in Christ". There are some parents who may not be part of a congregation but acknowledges that powerful source of life, who is mighty above all and holds onto that precious gift of appreciating and respecting that creator, the giver of life, who provides them with sustenance, and love, that sufficient word cannot express. For example one said she: "Believes in God but does not go to church." And other affirms the same" I would not go to church as much as I should, but I would pray. I am now learning to cope" while another even went further to explain, "My mother has a stronger faith in God, she does not believe in doctors".

Question 3: Describe the support you receive from the system, family or agency in the course of your current experience of having your child diagnosed with cancer? While discussing this question the main theme identified was: social support system.

Social support systems are essential for these parents whose children have been diagnosed with Cancer (Daniel and Zomerlei, 2017). Participants in the interviews were asked to describe their social support systems. Some mothers verbalized that they could rely on their husbands and other family members to aid in coping with the situation and for help when needed, even if it was to look after other children.

A few participants agreed that considerable family support helped them through their ordeal. Key informant four said; "I got plenty of support from my ex-husband, in-laws from both sides and other members of my family." While other participants felt that their entire family unit was their means of support as Key informant one mentioned, "...we spend more time as a family unit”.

Respondent one and three believed that the Just Because Foundation was very helpful and went above and beyond to meet their needs and other parents. Respondent one said, the Just Because Foundation helped a lot, Mrs. Chevaughn Joseph is an inspiration, you realize she is doing this for a purpose and genuinely loves kids”. Respondent three a father agreed.

Some parents agreed that other families facing the same situation were instrumental in providing a support system, Respondent one stated: "other families on the ward were also helpful,l you got to know other families whose children had the same problem”.

This showed that participants could rely on each when necessary. Another support system mentioned in this study was colleagues of those participants that were employed. Respondent five and a key informant two said co- workers played a large part as a means of support. Key informant two expressed, "my colleagues were very supportive when I could not go to work a co-worker would go and support me, and when I have to work a co -worker would go stay with him, even my Head Nurse use to say go ahead he would handle it."

Not having a good support system is a challenge to anyone when dealing with adversity especially a child being diagnosed with Cancer. Key informant three said, "I did not get the support from my employers, I still had to work permanent twelve-hour shifts". Respondent five said, "I don't have no support, but I have a nephew that I 
took care of and it bothered him a lot because him and my daughter was very very close and when her hair began to fall out, he was like oh my God and I guess she settled herself it would grow back and thing". Key informant three mentioned, "I am with my daughter twenty four seven, I take her to the clinic appointments and the rest of the day is spent attending to my daughter's needs".

\section{Discussion}

In reviewing the problem statement and research questions which outlined this study, it is realized that the analysis of the findings answers the research questions regarding challenges and coping strategies of parents with children diagnosed with paediatric Cancer. The summation of these findings reflects just a segment of the experiences of the ten participants in the three main themes; Reliance on Spirituality to Cope, Psychosocial Challenges and Social Support System.

\subsection{Reliance on Spirituality to Cope}

Paediatric Cancer is an enormous challenge for the patient, his/her family and the health care team. Parents search to find the meaning of their journey and some of the many feelings they may face are; anxiety, distress, hopelessness, pain and sadness just to mention a few. Spirituality and faith, appears to be one of the ways in providing important support and coping management. Much like a beacon serves to guide wayward ships in a storm, faith and spirituality can also serve as a guide during the often tumultuous journey of parenting a child diagnosed with childhood Cancer.

An attachment to or regard for things of the spirit as opposed to material or worldly interests" and faith is defined as "giving credit to, believing, trusting. Hope and spiritual perspective are important to helping patients derive positive meaning from their Cancer experience and Palliative care seeks to relieve the emotional, social, and spiritual distress produced by these life-limiting conditions, to assist in complex decision making, and to enhance quality of life (Weaver and Flannelly 2004). From the moment of diagnosis, through the many treatment modalities, until remission or death, a parent is consumed with his or her child's illness, treatment, and finding a cure. Parents require emotional, informational, spiritual, practical, physical, and psychosocial support to make it through this time of crisis. In times of stress, the spiritual realm may be a source of comfort and hope. Hope has been described as a protective factor for enhancing resilience and quality of life in paediatric Cancer reality based that a positive future exists for themselves and others. Additionally, according to Woodgate and Ateah (2008) children and families associated the spirit with the following four characteristics; a particular mind-set or state of mind, a force within or a need to persevere, a passion or wonder for living and a need to feel connected. The spirit as noted by one parent was just not one thing but was "a combination of positive attitude, determination, and perseverance".

Seven of the $10(70 \%)$ patients/families who acknowledged that spirituality was important to them opted for some limitation of support as compared with only 3 of the $10(30 \%)$ patients/families that expressed that spirituality was not important to them. The spiritual beliefs possessed by the parents appeared to offer a great deal of comfort to them while dealing with their child's illness. Spirituality was described as being highly personal and extremely powerful in its own right. Others described this power of prayer in terms of it actually affecting change in their children by having a direct, positive impact on their health or a positive light. It was evident that most of these men and women were willing to entrust their prayers to God and believed this practice to be a positive way in which they could support their child who was ill. Weaver \& Flannelly 2004 and Woodgate \& Ateah, 2008).

According to Weaver \& Flannelly, 2004 spirituality and religion have been shown to offer hope and have positive influence of the quality of life for those with Cancer and their loved ones. In 1997, Folkman added meaning-based coping to this model, suggesting that religion and spirituality allow for positive re-appraisal, and this serves a mechanism for reducing the negative impact of stressors and adverse life events. It is well established that disease and illness are stressful experiences, and often result in situations where individuals are forced to cope.

Findings from the data suggested a process of finding meaning which helps close relatives to let go of what they cannot control while holding on to what they can control. Thus, further studies are needed to fulfil this gap in the health care arena. In this context, this review is able to increase the awareness of health care professionals about their responsibility to identify the right moment to offer paediatric Cancer patients' families' spiritual support, providing to the child an unabridged and more humanized care. This article also has as objective to help parents to find other ways to cope with the disease's spiritual, psychological and social effects, bringing a body of knowledge about how spirituality can be an alternative to relieve the pain and turn them into a more proactive and integrated within the context of health quality improvement. 


\subsection{Psychosocial Challenges}

A diagnosis of childhood Cancer represents challenges for patients, family members, and health care workers. Parents deal with increased responsibilities as their role extends in general. The responsibilities falling on parents may increase the probability of responses such as anxiety, depression and guilt, sleep disorders, changes in diet, and perception of physical and emotional overload (James et al., 2002). Treatment also includes financial costs that result from the distance between home and hospital, leading to expenditures on transportation, accommodations, meals and phone calls.

As the experience of Cancer influences the emotional response of parents in relation to their child's needs, the ability of the child to deal with adverse situations is related to the parents' abilities to manage situations of crises.

One parent verbalized that "he took a tablet to prove to his son that everything will be okay after he took his medication"

One mother verbalized that "she did not allow visitors when her daughter's blood count were low"

Another stated "she cooked all her daughters' meal and did not purchase fast food"

Martinson et al., 1999, stated that the care system also usually changes, regardless of the cultural context including overprotective behaviour. Further, there is the psychosocial impact of treatment of childhood Cancer on parents. There is a negative impact of treatment such as; financial costs, changes in routine, changes in marital relationships, behavioural disorders as depression, anxiety, posttraumatic stress symptoms, and stress. Mothers tend to report higher levels of anxiety than fathers, whether at the time the diagnosis is disclosed or in other stages of the disease. High levels of anxiety may be correlated with post-traumatic stress, difficulties making decisions, loss of memory, difficulty concentrating, insomnia and treatment avoidance (Santacroce, 2002). Parents reporting high levels of anxiety at the diagnosis usually continue to experience significant manifestations even after the treatment ends.

In this study, it was observed that parents initial response to the diagnosis, were with behaviour indicative of depression, such as persistent sadness, pessimism, hopelessness, guilt, and helplessness which lasted for several months. One parent questioned "what she did wrong to deserve this kind of heartache"

Leavitt et al.,( 1999), states explanations of the disease are characterized by guilt and spiritualistic explanations, which include the belief that the disease is a kind of payment for some bad deed in past life or divine punishment.

The availability of social support from family members, friends, co-workers, and neighbours was also extremely important (McGrath, 2001). Dealing with the disease involves seeking professional help, support among friends and neighbours, focusing on the present instead of focusing on future prospects, and emphasizing the care provided to the child (Leavitt et al.1999). In our study social support was available and parents agreed that it played a significant role in coping throughout their challenging times.

\subsection{Social Support Systems}

Social support systems identified as one of the themes coming out of this study was linked to how social support is affected by lived experience of parents of children diagnosed with Cancer. One of the areas highlighted in this of this study was 'support' of the family. Support is very essential however, from the moment of diagnosis, the family is catapulted into a new reality that is both threatening and confusing. Close friends and significant others also feel the brunt of the confusion. The child and the entire extended family enter a contract with uncertainty about prognosis, treatment, outcome and impact. Sometimes they feel uncomfortable asking friends and family for assistance. Some parents feel the need to do what they have to by themselves; they do not know how to respond when people offer to help. They themselves are uncertain what they need (Austin, Onuoha and Dyer-Regis 2016). People are largely rational in their thoughts and actions and will take the best health-supporting action if they; feel that it is possible to address a negative health issue, have a positive expectation that taking the proposed action will be effective in addressing the issue and believe they are able to take the proposed action. This study revealed by the response of participants that a great amount of support was given by family members, significant others, churches and communities. Parents have also found support from other parents of children who have Cancer. This helps build a working relationship and they are also able to share information. No one understands better than another family in the same position.

As such it was noticed that most participants from their response preferred to be at the bedside of their son/daughter each day. It is acknowledged that people differ in their reactions to stressful events and this may depend on many factors such as their previous experience and differences in their roles, responsibilities and 
coping mechanisms. So to show fear or need for support may indicate weakness on the parent's behalf and the want to establish some level of control hence the reason for not refusing help given but ensuring that they are present most or all the time even if support is available (Global Journal of Health Science 2013).

\section{Recommendation}

This study explored the lived experiences of parents of the Paediatric hospital in Trinidad and Tobago and described how cancer had affected their lives, whether psychologically, psychosocially, spiritually or financially. We recommend that further comprehensive research is needed in studying Pediatric Cancer inclusive of Tobago and other Caribbean islands.

\section{Conclusion}

This study revealed that the lived experiences of parents who care for their children diagnosed with Cancer, feel like a never-ending struggle. Regardless of the substantial progress in the treatment of Cancer, childhood Cancer is still emotionally, physically, and psychologically challenging for parents. This qualitative study provided a culturally sensitive perspective of parental responses embedded in the Trinidad's culture. Consequently, findings also emphasize the importance of exploring with the parents their subjective perceptions of the situation. Grief, anger, anxiety, pain, sadness, guilt, hopelessness and frustration must be handled in a positive way to enable the parents to be able to cope effectively and care for their children with paediatric Cancer. Although parents embraced their caregiving role, reporting acquired meaning and purpose, the key themes of spiritual reliance to cope, psychosocial challenges and social support system highlight the substantial demand for both physical and emotional support beyond that which can be provided by extended family and friends.

The theme highlighted in this study offer opportunities for additional qualitative and quantitative research in the field of oncology and its impact on Trinidadian parents and the Trinidad family systems and dynamics. Therefore further research is needed from the nursing perspective that should be conducted with greater emphasis in paediatric oncology. There should also be an increase in the training of speciality nurses in the field of paediatric oncology and in the improvement of nurses' attitudes towards the emotional, psychosocial, mental and physical needs of parents of children suffering with Cancer.

This study has implication for nursing, the governments and other health policy and supportive agencies as the result highlighted the toll of living with cancers and on the lives of parents and families of children diagnosed with cancer.

\section{References}

Austin, M., Onuoha, P., \& Dyer-Regis, B. (2016). Lived Experiences of Parents of School-aged Children with Hearing Impairment in North Trinidad. IOSR Journal of Nursing and Health Science, 5(6), 46-51. https://doi.org/10.9790/1959-0506044651

Björk, M., Wiebe, T., \& Hallström, I. (2005). Striving to survive: Families' lived experiences when a child is diagnosed with Cancer. Journal of Pediatric Oncology Nursing, 22(5), 265-275. https://doi.org/10.1177/1043454205279303

Bodkyn, C., \& Lalchandi, S. (2010). Incidence of Childhood Cancer in Trinidad and Tobago. West Indian Medical Journal, 59(5), 565-8. Available at: https://www.mona.uwi.edu/fms/wimj/article/1288 [Accessed 9 Apr. 2017].

Cayon, A. (2017). PAHO WHO | Regional experts on childhood Cancer join forces to reduce Inequities and increase access to care. Pan American Health Organization / World Health Organization. Available: http://www.paho.org/hq/index.php?option=com_content\&view=article\&id=12976\%Aexperts-on childhood-Cancer-join-forces-to-reduce-inequities-and-increase-access-to care $\&$ catid $=3788 \% 3$ ACancer-events $\& I t e m i d=42322 \&$ lang $=$ en [Accessed 12 Jun. 2017].

Changingminds.org. (2017). Health Belief Model. [online] Available at: http://www.changingminds.org/explainations/belief/health_belief_model.htm [Accessed 20 Jul. 2017].

Cho, S., Yang, M., Yim, S., Park, J., Lee, J., Eom, Y., Jang, I., ... Kim, H. (2009). Prevalence and risk factors of irritable bowel syndrome in Korean adolescent girls: a school-based study. International Journal of Nursing Studies, 46(1), 76-84.

Clarke, J. N., \& Fletcher, P. (2003). Communication issues faced by parents who have a child Diagnosed with Cancer. Journal of Pediatric Oncology Nursing, 20(4), 175-191. https://doi.org/10.1177/1043454203254040 
Dahlquist, L. M., Czyzewski, D. I., \& Jones, C. L. (1996). Parents of children with Cancer: A longitudinal study of emotional distress, coping style, and marital adjustment two and twenty months after diagnosis. Journal of Pediatric Psychology, 21(4), 541-554. https://doi.org/10.1093/jpepsy/21.4.541

Daniel, R., \& Zomerlei, D. (2017). Family resilience following a diagnosis of pediatric Cancer: Parent experiences of social support, coping, and adaptation. Doctor of Philosophy. Michigan StateUniversity.

Engel, G. (1978). The biopsychosocial model and the education of health professionals annals of the New York academy of science.

Han, H.. Cho, E, Kim, D., \& Kim, J. (2009). The report of Coping strategies and psychosocial adjustments in Korean mothers of children with cancer. Psychooncology. Sep, 18(9), 956-964. https://doi.org/10.1002/pon.1514

Folkman, S. (1997). Positive psychological states and coping with severe stress. Soc. Sci Med., 45(8), 1207-21. https://doi.org/10.1016/S0277-9536(97)00040-3

James, K., Keegan-Wells, D., Hinds, P. S., Kelly, K. P., Bond, D., Hall, B., Mahan, R., Moore, I. M., Roll, L., \& Speckhart, B. (2002). The care of my child with Cancer: Parent's perceptions of caregiving demands. Journal of Pediatric Oncology Nursing, 19(6), 218-228. https://doi.org/10.1177/104345420201900606

Janelle De Souza, J. (2017). Minister: Report all Cancer cases. Trinidad and Tobago Newsday. Available at: http://www.newsday.co.tt/news/0,150535.html [Accessed 9 Apr. 2017].

Leavitt, M., Martinson, I. M., Liu, C. Y., Armstrong, V., Hornberger, L. Q., Zhang, J., \& Han, X. P. (1999). Common themes and ethnic differences in family caregiving the first year after diagnosis of childhood Cancer: Part II. Journal of Pediatric Nursing, 14(2), 110-122. https://doi.org/10.1016/S0882-5963(99)80045-1

Martinson, I. M., Leavitt, M., Liu, C. Y., Armstrong, V., Hornberger, L., Zhang, J. Q., \& Han, X. P. (1999). Comparison of Chinese and Caucasian families caregiving to children with Cancer at home:Part I. Journal of Pediatric Nursing, 14(2), 99-109. https://doi.org/10.1016/S0882-5963(99)80044-X

McGrath, P. (2001). Findings on the impact of the treatment for childhood acute lymphoblastic leukaemia on family relationships. Child and Family Social Work, 6(3), 229-237. https://doi.org/10.1046/j.1365-2206.2001.00200.x

Onuoha, C. A., Dyer-Regis, B., \& Onuoha, P. C. (2017). Implementation levels of a life-skill based school health programme in a Caribbean Country. International Journal of Health Sciences and Research, 7(4), 353-359.

Polit, D., \& Beck, C. (2018). Essentials of nursing research: appraising evidence for nursing practice, $9^{\text {th }}$ edition: Wolters Kluwer Health, Philadelphia.

Santacroce, S. (2002). Uncertainty, anxiety, and symptoms of posttraumatic stress in parents of Children recently diagnosed with Cancer. Journal of Pediatric Oncology Nursing, 19(3). https://doi.org/10.1177/104345420201900305

Siegel, R., Miller, K., \& Jemmal, A. (2016). Cancer Statistics 2016. CA: A can journal for Clinicians, 7-30. https://doi.org/10.3322/caac.21332

Theodore, K. A. L., Gitens-Bayne, K., Edwars-Wescotts, P., Mc Clean, R., \& Laptiste, C. (2011, October 06). Situation Analysis. Retrieved from https://www.unicef.org/sitan/index_43340.html

Weaver, A. J., \& Flannelly, K. J. (2004). The role of religion/spirituality for cancer patients and their caregivers. South Med J., 97(12), 1210-4. https://doi.org/10.1097/01.SMJ.0000146492.27650.1C

Woodgate, R. L., \& Ateah, C. (2008). Living in a World of Our Own: The Experience of Parents Who Have a Child With Autism. Qualitative Health Research, 18(8), 1075-1083. https://doi.org/10.1177/1049732308320112

Zomeriel, D. R. (2016). Family resilience following a diagnosis of pediatric cancer: parent Experiences of social support, coping, and adaptation. A dissertation. Submitted to. Michigan state university in partial fulfilment of the requirements for the degree of. Human development.

\section{Copyrights}

Copyright for this article is retained by the author(s), with first publication rights granted to the journal.

This is an open-access article distributed under the terms and conditions of the Creative Commons Attribution license (http://creativecommons.org/licenses/by/4.0/). 